Original article

\title{
NUTRITION AS A BONES HEALTH FACTOR WITH SIGNIFICANT INFLUENCE
}

\author{
Rositsa Chamova $^{1}$, Maria Panteleeva ${ }^{2}$, Eliyana Ivanova ${ }^{1}$ \\ 1) Department of Hygiene and Epidemiology, Faculty of Public Health, Medi- \\ cal University - Varna, Bulgaria \\ 2) Department of Disaster Medicine and Maritime Medicine, Faculty of Public \\ Health, Medical University - Varna, Bulgaria.
}

\begin{abstract}
Osteoporosis is a global health problem with increasing importance. It is a chronic, debilitating disease characterized by low bone density and deterioration of the micro architectonics of bone tissue. Although genetic factors largely determine the bone size and density, factors such as healthy eating, good physical activity and avoiding alcohol and smoking also play a key role. At all ages, healthy eating is an important factor in bone health.

Aim: To study the eating habits that are important for bone health in women from Varna.

Methods: A cross-sectional study of the eating habits of 139 women in Varna was conducted between January 2018 and March 2019. Questions, giving information on diet, frequency of consumption of certain food groups and beverages, affecting bone density, physical activity, demographic indicators are included in the questionnaire. Descriptive analysis of the data is done with SPSS version 19.

Results: The average age of the participants was $29.86 \pm 13.60$ years. Daily consumption of milk and dairy products was found among $36.7 \%$ and $32.4 \%$ of the respondents respectively. The relative share of respondents who consume fish $1-2$ times a week is $33.1 \%$. The daily consumption of fruits and vegetables is $47.5 \%$ and $56.8 \%$ respectively.

Conclusion: Nutrition plays an important role in reducing the risk of osteoporosis by affecting the development and maintenance of bone mass.
\end{abstract}

Keywords: osteoporosis, bone health, nutrition,

\section{INTRODUCTION:}

Osteoporosis is a global health problem with increasing importance. Osteoporotic fractures are among the most common causes of disability worldwide [1]. Osteoporosis is a progressive metabolic disease of the skel- eton, characterized by a decrease in the bone density. It could be primary and secondary (after long-term corticosteroid treatment, in Cushing's disease).In adulthood, bone density depends on the peak reached during the growth period and the rate of bone loss as we age. Some of the factors affecting bone mass cannot be influenced (gender, age, genotype and race) while others (hormonal status, physical activity levels, smoking and alcohol consumption, diet) can be modified.

Healthy eating, including adequate intake of energy and nutrients (macro and micronutrients), is a factor in bone health at all ages.

Aim: To study the important for bone health eating habits in women in Varna.

\section{METHODS:}

During the period January 2018 - March 2019, a section study of eating habits of 139 women was conducted in Varna. The choice of the study group is determined by the fact that women are more at risk of developing osteoporosis. Questions, giving information on diet, frequency of consumption of certain food groups and beverages, affecting bone density, physical activity, demographic indicators are included in the questionnaire. Participation in the survey is voluntary. Statistical data analysis is done with SPSS version 19. Descriptive analysis of the data is used.

\section{RESULTS:}

The mean age of the respondents is $29.86 \pm 13.60$ years. Most of them live in the city - $95.7 \%$ compared to $4.3 \%$ living in the countryside. The relative share of women who observe a certain eating regime is $9.4 \%$, while such is absent in 59\%. The relative share of women who eat three times a day is the highest (Figure 1). 
Fig. 1. Distribution of respondents $(\%)$ according to the regime of eating

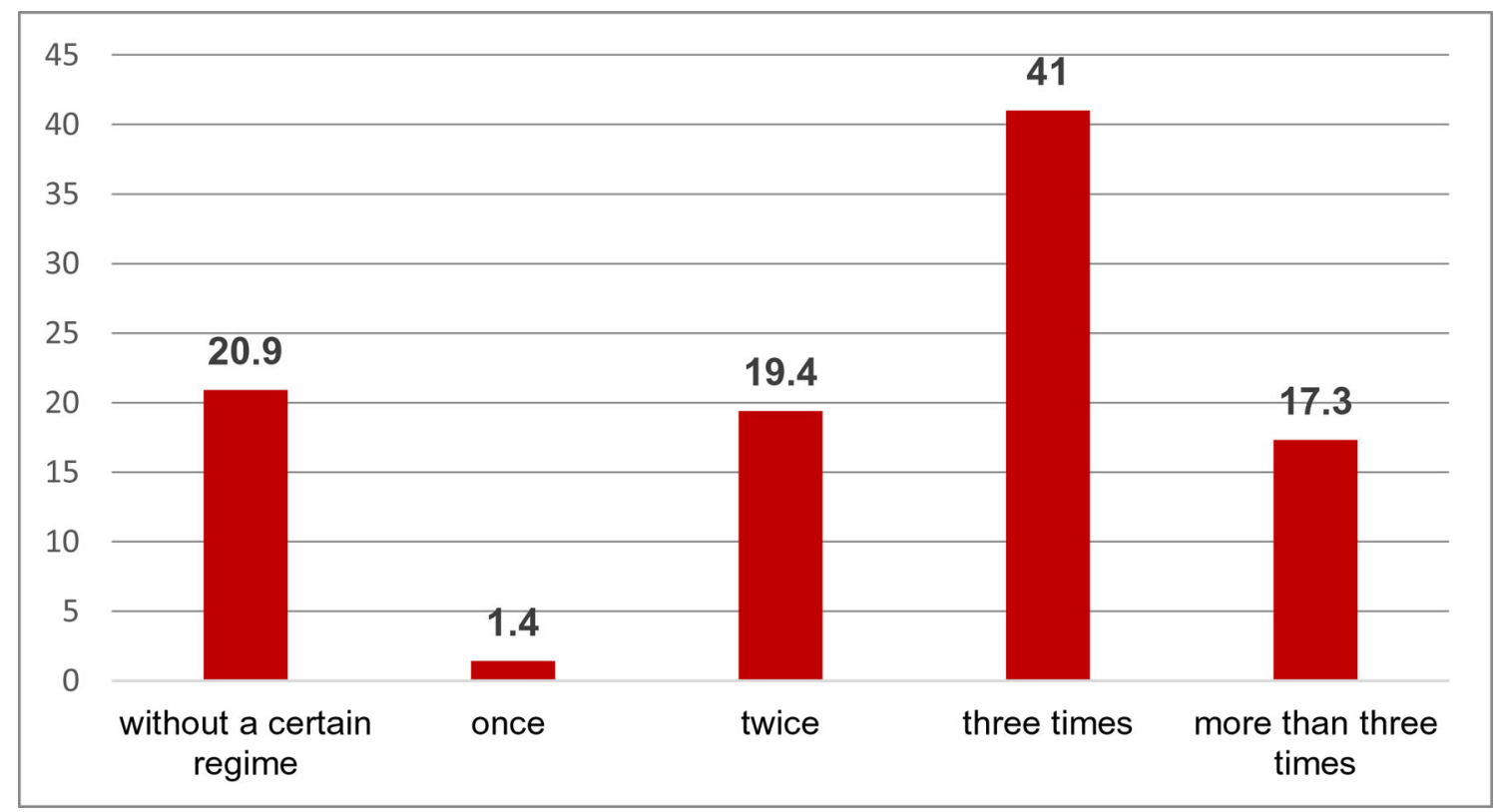

Adequate protein intake is essential to optimally increase bone mass during childhood and adolescence and to maintain it with age. In human nutrition, there are animal and vegetable protein sources. These include fish, meat, eggs, milk and dairy products, legumes, cereals and nuts. Most of the women who took part in the study, regularly consumed foods that were sources of wholesome animal protein. Those, who do not consume fish or meat are $9.4 \%$ and $8.6 \%$ respectively (Figure 2 ).

Fig. 2. Frequency of consumption of food which is a source of animal protein (\%)

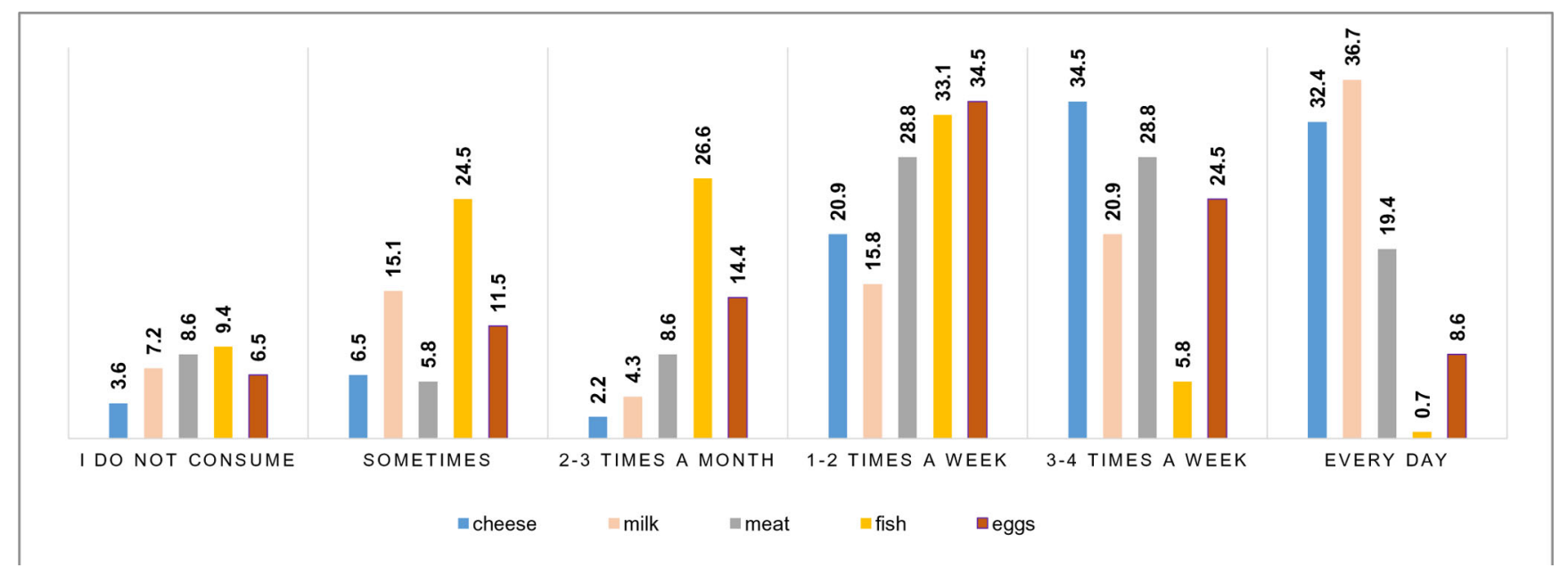

The frequency of consumption of plant food sources of protein is shown in Figure 3. 
Fig. 3. Frequency of consumption of food which is a source of vegetable protein (\%)

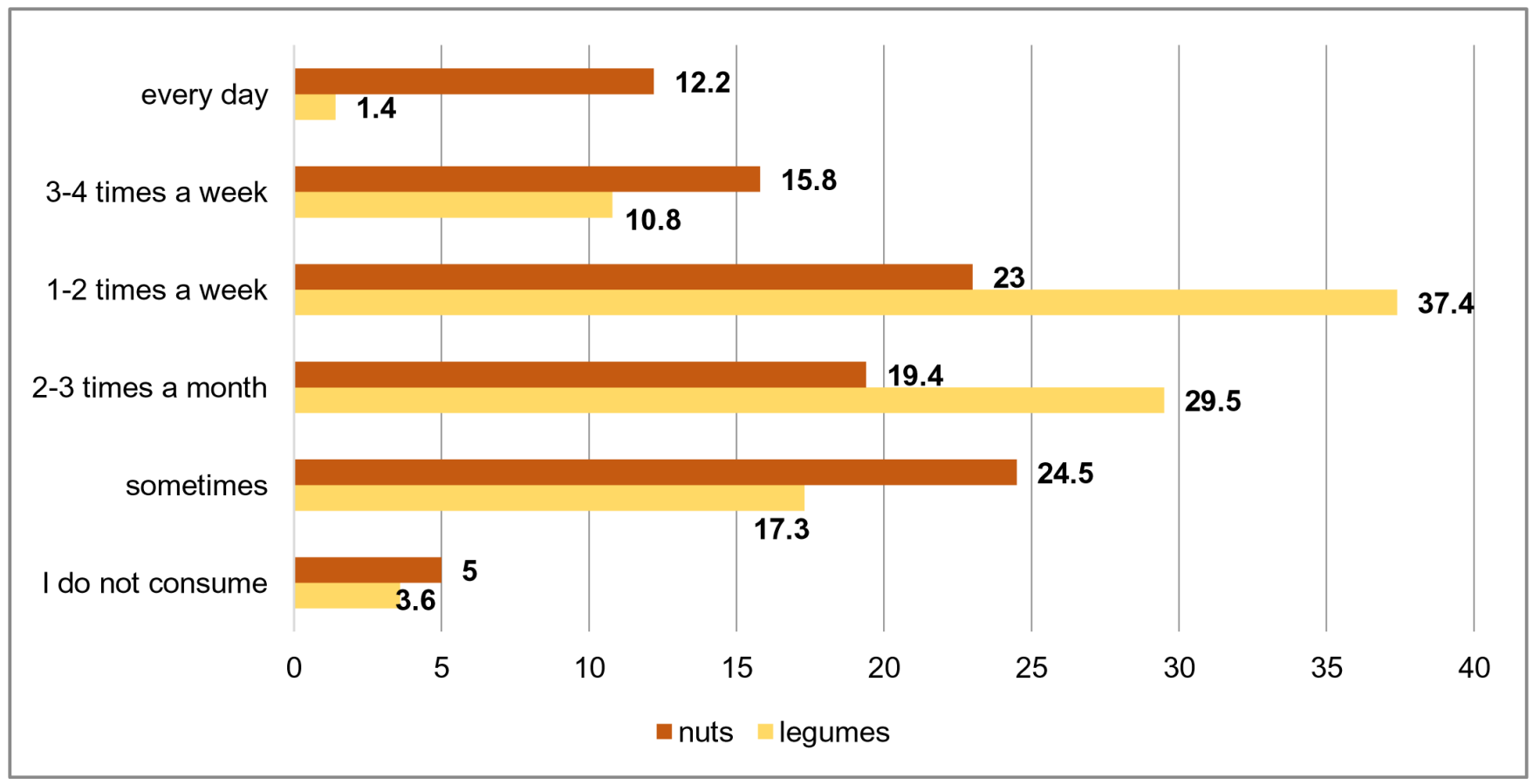

Micronutrient with a decisive role in bone strength is calcium. It is required for normal skeletal growth and development. Adequate calcium intake is crucial for achieving optimal bone mass peak and for the degree of bone loss associated with aging.

The results of our study show that $36.7 \%$ of the surveyed women daily consume milk, which is the source of the most easily absorbed calcium. Good sources of macronutrients are dairy products, which according to current recommendations is desirable to be consumed daily.32.4\% of the respondents report daily consumption of dairy products. The relative share of women in whose diet milk and milk products are rarely present (sometimes) is $15.1 \%$ and $6.5 \%$, respectively. Milk and dairy products are not consumed by $7.2 \%$ and $3.6 \%$ of the respondents respectively, which defines these groups as being at risk of developing osteoporosis, due to the low consumption of biologically active calcium.

Fish play an important role in the healthy diet of humans. It is a good nutritional source of high protein and vitamin D nutrients with a preventive effect on osteoporosis. Fish consumption once or twice a week (which is the current recommendation), report $33.1 \%$ of the respondents. Some of the women surveyed do not consume fish $(9.4 \%)$. During the winter months, when fish is the main source of vitamin $\mathrm{D}$, the likelihood of vitamin $\mathrm{D}$ deficiency in this group increases.

Fruit and vegetables are important for bone health as sources of vitamins ( $\mathrm{C}, \mathrm{A}, \mathrm{K})$, minerals ( $\mathrm{Zn}, \mathrm{Mg}, \mathrm{K}$, etc.), antioxidants, organic acids and alkaline salts. With regard to the frequency of consumption of these food groups, the highest percentage is the relative share of women who stick to current recommendations for their daily consumption. Every day $47.5 \%$ of the respondents consume fruit and $56.8 \%$ of the respondents consume vegetables.

Risk factors for reducing bone density include frequent consumption of coffee and alcohol [2]. With risky consumption (three or more coffees per day) are $8.6 \%$ of the respondents (Figure 4).

Fig. 4. Frequency of coffee consumption (\%)

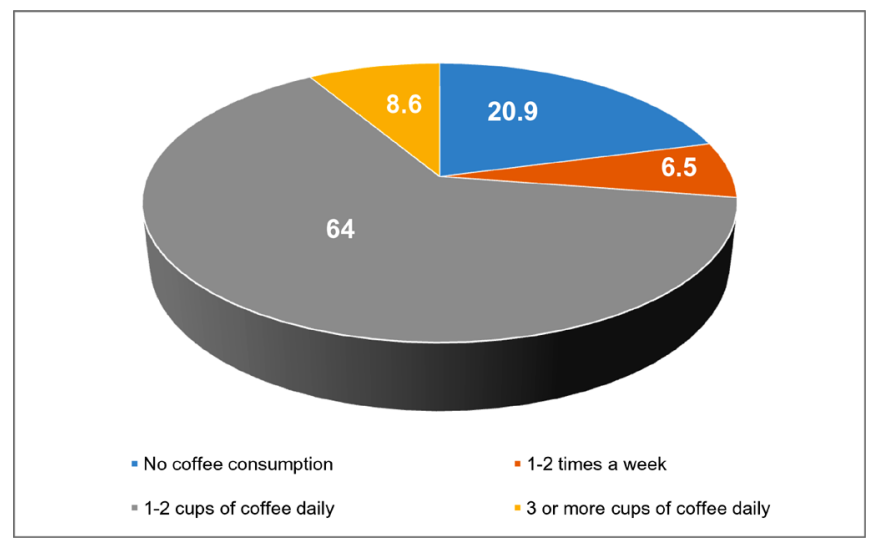

The study of the frequency of alcohol consumption as a risk factor for osteoporosis shows that the relative share of women who consume alcoholic beverages several times a month is the highest $-36.7 \%$. Daily consumption of alcohol is found in $5.0 \%$ of women, which, given the young age of the respondents, is an unfavorable trend. Those who never use alcohol are $21.6 \%$. 


\section{DISCUSSION:}

Knowing the risk factors for osteoporosis is the most successful way to prevent this disease. Many women in Bulgaria are not well informed about how to maintain their bone health [3]. Healthy eating is one of the factors that promote bone health. The mechanisms of nutrients affecting the bones include changes in bone structure and bone metabolism, effects on endocrine and/or paracrine systems, and on the homeostasis of calcium and other mineral elements with bone impact.

Protein. About half of the bone volume is protein. Bone remodelling involves the synthesis of a new protein matrix that requires a continuous supply of nutritional protein. Langsetmo et al. found that low protein intake may increase the risk of fractures due to the determinant effect of protein on bone density [4]. Studies on the link between eating patterns and bone fractures have shown that higher consumption of animal protein compared to plant protein is associated with greater bone loss, which increases the risk of osteoporosis [5].

It is assumed that the decomposition of the animal protein releases more acidic products compared to the plant protein, which increases the excretion of calcium by the urine and results in a negative calcium balance. Other studies do not support the relationship of negative calcium balance with animal protein sources compared to plant sources [6]. It is believed that the loss of calcium in the urine can be partially compensated by the phosphate association in most foods with high protein content.

According to the results' analysis, there are individuals among the respondents who do not consume any of the five food groups, the main sources of animal protein. Most of the respondents in this survey follow the recommendations for including legumes in their diet once or twice a week.

Calcium. The role of calcium in bone health at all ages has been proven. In addition to the amount of calcium in food, the degree of its absorption by the body is also essential. A number of nutrients can improve calcium absorption. Milk ingredients such as lactose, lactulose and casein phosphopeptides favour the solubility and absorption of calcium. Calcium from dairy products is easily absorbed in the intestine. Dairy foods are also good sources of protein and other microelements that are important for bone health. Other good nutritional sources of calcium are some green vegetables such as broccoli, kale; canned fish with soft edible bones such as sardines and salmon; nuts - especially Brazilian walnuts and almonds; some fruits such as oranges, apricots and dried figs; tofu. The plant components of fibres, phytate and oxalic acid suppress calcium absorption. The recommended dietary intake of calcium varies with age [7].

However, the results of our study show that some women do not consume milk and dairy products. As a consequence, they are at higher risk of developing a calcium deficiency.

Vitamin D plays an important role in helping calcium absorption from food. It is necessary for the renewal and mineralization of bone tissue, for maintaining immunity and muscle tone. In order to achieve genetically engineered peak bone density, it is important to ensure adequate vitamin D intake, especially during adolescence. A representative study among girls from Varna showed that $68 \%$ were at risk of vitamin D deficiency in the cold season due to low fish consumption [8]. The results of our study are similar - only $33 \%$ of the women consume fish once or twice a week, the rest consume fish less often or do not consume it at all. In children, severe vitamin D deficiency leads to rachitis, which results in growth retardation and bone deformity. Osteomalacia occurs in adults due to poor bone mineralization. Vitamin D is produced in the skin by the UVB rays of the solar spectrum. For the population in the northern latitudes during the winter months, when the intensity of sunshine is very low, vitamin D is supplied by food and supplements. Nutritional sources of vitamin D are limited and include oily fish - salmon, tuna, sardines and mackerel; egg yolk and liver. In some countries, foods are enriched with vitamin $\mathrm{D}$, which is labeled - milk and other dairy foods, margarine, stored foods and snacks.

Vitamin K. Recent studies have shown that vita$\min \mathrm{K}$, as a multifunctional vitamin, plays a key role in maintaining bone strength and has a positive effect on bone metabolism. Vitamin K promotes osteoblastic differentiation and increases the level of some bone formation markers (eg alkaline phosphatase and insulin-like growth factor) [9], enhances the transcription of specific genes in osteoblasts and activates bone-related vitamin K-dependent proteins that play an important role in extracellular bone matrix mineralization - Osteocalcin, matrix Gla protein, growth arrest-specific 6 protein (Gas 6), and protein $\mathrm{S}$ [10 ]. Vitamin K prevents bone resorption through its anti-catabolic effects by suppressing osteoclast differentiation and inhibiting osteoblastic apoptosis [9].

Vitamin $\mathrm{K}_{1}$, known as phylloquinone or phytonadione, is of plant origin. It is contained in fruits and vegetables (kiwi, avocado, broccoli, green grapes and lettuce), as well as oils (rapeseed, soybean and olive oil). Food sources of vitamin K2 (menaquinone) are fish, liver, milk, vegetables and eggs. In Bulgaria, the daily recommended vitamin $\mathrm{K}$ requirements are $60 \mathrm{mgm} /$ day for women and 75-80 $\mathrm{mgm} /$ day for men [7].

Other nutrients such as magnesium, zinc, copper, iron, fluoride, vitamins $\mathrm{A}, \mathrm{C}$ and $\mathrm{B}$ are required for normal bone metabolism.

Dairy products and bone health. There was a significant positive relationship between dairy intake and 
bone density [11]. The Postmenopausal Health Study reports that women who received approximately $1200 \mathrm{mg}$ of calcium and $7.5 \mathrm{mcg}$ of vitamin D (300 IU) via dairy products increased total bone density, that of the hip and spine more than those who received only calcium supplement or control group [12]. According to a report by the Dietary Guidelines Advisory Committee for 2005, five out of eight observational studies found that dairy consumption was significantly associated with a reduced risk of breakage [11]. Cheng et al. demonstrate the benefits of effects on bone mass of calcium from a nutritional source (cheese) compared to those from dietary supplements in adolescent girls [13].

Similar to the results of our study on the consumption of milk and dairy products are those in a study on the territory of Varna among more than 200 young women (ages 18-20). Only $28.5 \%$ of them consume milk daily. There is a significant positive correlation between low milk consumption and Body Mass Index (BMI) in girls ( $\mathrm{r}$ $=0.409 * *, \mathrm{p}<0.001)[14]$.

Coffee. The results of studies examining the relationship between coffee consumption and osteoporosis or bone mineral density are ambiguous.

Some studies have found that high consumption of coffee (4 cups and more per day) increases the risk of osteoporotic fractures [2]. In other studies, no significant relationship was found between coffee consumption and bone density [15].
Hallström H et al. (2013) found that high coffee consumption was significantly associated with a small decrease in bone density but not with an increased risk of osteoporotic fractures among 5022 Swedish women age over 40 years [16]. According to other authors, moderate coffee consumption is significantly associated with bone density increase [17].

More research is needed in this regard.

Fruits and vegetables. The link between the intake of fruits and vegetables and the prevention of bone fractures in adulthood is not clear enough. Studies in women have found an increased risk of hip fracture with very low consumption of fruits and vegetables. [18, 19]. Half of the participants in our survey consume fresh fruits and vegetables daily. Other studies in our country show that young Bulgarians exhibit risky eating behavior - only $20 \%$ of them consume an adequate amount of fresh fruit [20].

\section{CONCLUSION:}

The majority of women of reproductive age in Varna follow the national recommendations for healthy eating. However, there are also respondents among them who are at risk of nutritional deficiencies with adverse effects on bone health.

The severity of osteoporosis can be reduced by certain lifestyle changes. Nutrition plays an important role in reducing the risk of osteoporosis by affecting the development and maintenance of bone mass.

\section{REFERENCES:}

1. Chang $\mathrm{H}-\mathrm{C}$, Hsieh C-F, Lin Y-C, Tantoh DM, Ko P-C, Kung Y-Y, et al. Does coffee drinking have beneficial effects on bone health of Taiwanese adults? A longitudinal study. $B M C$ Public Health. 2018 Nov 20; 18(1): 1273. [PubMed] [Crossref]

2.Silva TR, Franz R, Maturana MA, Spritzer PM. Associations between body composition and lifestyle factors with bone mineral density according to time since menopause in women from southern Brazil: a cross-sectional study. BMC Endocr Disord. 2015; 15(1):71.

3. Najdenova D, Kavaldzhieva B, Dimitrova T, Hristozov K. [Factors of bone health and information about that in women.] Proceedings of the Jubilee Scientific Conference "MHAT Plovdiv" 55 years. 15 November 2007 , pp.179-184.

4. Langsetmo L, Barr SI, Berger C,
Kreiger N, Rahme E, Adachi JD, et al. Associations of Protein Intake and Protein Source with Bone Mineral Density and Fracture Risk: A Population-Based Cohort Study. J Nutr Health Aging. 2015 Oct;19(8):861-8. [PubMed] [Crossref]

5. Weikert C, Walter D, Hoffmann $\mathrm{K}$, Kroke A, Bergmann MM, Boeing H. The relation between dietary protein, calcium and bone health in women: results from the EPIC-Potsdam cohort. Ann Nutr Metab. 2005; 49:312-8

6. Khoo C, Woo J, Leung P, Kwok A, Kwok T. Determinants of bone mineral density in older postmenopausal Chinese women. Climacteric. 2011; 14(3): 378-83.

7. [Ordinance No.1/22 Jan. 2018 on the physiological norms of nutrition of the population.] [in Bulgarian] Ministry of Health. [Internet]

8. Hristova DN. [Body composition and nutritional status assessment in adolescents] [monograph] ISBN 978619-7137-29-3. Varna (Bulgaria): zape4at.com; 2015. 87-89 p. [in Bulgarian].

9. Villa J.K.D, Diaz M.A.N, Pizziolo V.R., Martino H.S.D. Effect of vitamin $\mathrm{K}$ in bone metabolism and vascular calcification: A review of mechanisms of action and evidences. Crit. Reviews in Food Science and Nutrition, 2017; 57 (18; 3959-3970.

10. Beulens JWJ, Booth SL, Van Den Heuvel EGHM, Stoecklin E, Baka A, Vermeer C. The role of menaquinones (vitamin K2) in human health. Br J Nutr. 2013; 110 (8): 1357-1368.

11. Nicklas TA, Weaver C, Britten P, Stitzel KF. The 2005 Dietary Guidelines Advisory Committee: developing a key message. J Am Diet Assoc. 2005 Sep;105(9):1418-24. [PubMed] [Crossref] 
12. Manios Y, Moschonis G, Trovas G, Lyritis GP. Changes in biochemical indexes of bone metabolism and bone mineral density after a 12-mo dietary intervention program: the Postmenopausal Health Study. Am J Clin Nutr. 2007; 86:781-789.

13. Cheng S, Lyytikainen A, Kroger H, Lamberg-Allardt C, Alen M, Koistinen A, et al. Effects of calcium, dairy product, and vitamin D supplementation on bone mass accrual and body composition in 10-12-y-old girls: a 2-y randomized trial. Am J Clin Nutr. 2005; 82: 1115-1126, Quiz 1147-1148.

14. Hristova DN, Dimitrova TT, Nikolov PN. Bone health factors in adolescents from Varna. $J$ of IMAB. 2018 Oct-Dec;24(4):2290-2294. [Crossref]
15. Choi E-J, Kim K-H, Koh Y-J, Lee J-S, Lee D-R, Park SM. Coffee consumption and bone mineral density in Korean premenopausal women. Korean J Fam Med. 2014; 35(1): 11-8.

16. Hallström H, Byberg L, Glynn A, Lemming EW, Wolk A, Michaëlsson K. Long-term coffee consumption in relation to fracture risk and bone mineral density in women. Am J Epidemiol. 2013; 178(6):898-909.

17. Choi E, Choi K-H, Park SM, Shin D, Joh H-K, Cho E. The benefit of bone health by drinking coffee among Korean postmenopausal women: a cross-sectional analysis of the fourth \& fifth Korea national health and nutrition examination surveys. PLoS One. 2016; 11(1): e0147762.

18. Brondani JA, Comim FV, Flores
LM, Martini LA, Premaor MO. Fruit and vegetable intake and bones: A systematic review and meta-analysis. PLoS One. 2019 May 31;14(5): e0217223. [PubMed] [Crossref]

19. Benetou V, Orfanos P, Feskanich D, Michaålsson K, Pettersson-Kymmer U, Eriksson S, et al. Fruit and Vegetable Intake and Hip Fracture Incidence in Older Men and Women: The CHANCES Project. $J$ Bone Miner Res. 2016 Sep;31(9):174352. [PubMed] [Crossref]

20. Naydenova D. [Nutritional Behavior, Anthropometric Indicators, Physical Activity and Physical Ability of Normal, Underweight and Overweight Young Men and Girls] [dissertation]. Medical University - Varna. 2014. 72p [in Bulgarian].

Please cite this article as: Chamova R, Panteleeva M, Ivanova E. Nutrition as a bones health factor with significant influence. J of IMAB. 2020 Oct-Dec;26(4):3426-3431. DOI: https://doi.org/10.5272/jimab.2020264.3426

Received: 11/11/2019; Published online: 10/11/2020

Address for correspondence:

Dr Rositsa Chamova, MD, PhD

Department of Hygiene and Epidemiology, Medical University - Varna, 55, Marin Drinov str., 9000 Varna, Bulgaria.

E-mail: rchamova72@gmail.com 